Published in Haukkala H., van de Wetering C. \& Vuorelma J. (eds) Trust in International Relations: Rationalist, Constructivist, and Psychological Approaches. London: Routledge.

ISBN: 978-1-138-63008-6 . https://doi.org/10.4324/9781315209838

\title{
7. Taking stock of the trust study in International Relations
}

\section{Tuomas Forsberg}

Trust or at least the quest for it is present everywhere in human and social life - and also in world politics. Although practitioners have almost always understood its importance, it has taken a long time for researchers to discover - or to some extent to rediscover - the concept of trust in the field of International Relations. There is now an expanding and forward-looking body of research on trust in IR that seeks to make analytical and theoretical sense of the concept, apply it to new empirical contexts as well as to solve explanatory puzzles with the help of the concept.

This book is an excellent example of this growing trust research, representing a variety of perspectives and examining its significance via empirical case studies in International Relations. We can no longer depart from the assumption that trusting relations are marginal in world politics and that distrust is the natural point of departure for conducting international affairs. Instead, trust should be seen as a central and instrumental concept in tackling pressing problems from security to trade and environment that we are encountering in today's world shaped by suspicion and uncertainty. In short, where trust does not exist, we should think how to create trust in order to make human and social life better.

Yet, having said this, there is still some work to do in order to place trust among the central concepts of the discipline. Trust is not, for example, listed as a key concept in International Relations in neither of the two edited volumes that discuss more than forty key concepts in the discipline (Diez, Bode and Fernandes da Costa 2011; Roach, Griffiths and O'Callaghan 2014). The key articles on trust in the field of the IR have gathered less than 100 citations (some even less than 10) in refereed journals. Neither is trust indexed as a key word in any of the several IR textbooks I surveyed.

There is a variety of avenues to enhance our understanding of trust in International Relations. Although research on trust has been extensively conducted in many neighbouring disciplines, it is not always easy to create interdisciplinary knowledge and transfer existing research findings to a new field (Neal et al. 2016). For example, there is a dynamic research field focusing on political trust but much of the research relies on narrowing down the concept of trust to political trust and accepting empirical operationalisations of the concept (Zmerli and van der Meer 2017). Indeed, the concept is often analysed in idiosyncratic ways, which has not resulted in much cumulative knowledge (Hupcey et al. 2001).

A telling example is that the outgoing editor of the Journal of Trust Research that was established to advance knowledge on trust, characterises the areas where progress has been made during the first six years of the journal in terms of more sophisticated ways of addressing various dualisms and complexities ( $\mathrm{Li}$ 2017). In other words, progress is more evident in the increased number of perspectives and the more refined way of understanding the dividing issues rather than in the form of shared knowledge. Even within IR, as the editors of this volume note, there are perhaps too numerous 
and sometimes unnecessarily complex conceptualisations of trust. The flipside of conceptual richness is conceptual confusion.

In this concluding chapter, I will not deal with the articles of this volume in detail but rather address some general themes that cut across them. The purpose of the chapter is to help us to reflect what research on trust has achieved and could achieve in IR. I will first discuss the concept and then the theories, although these are partly overlapping issues. Finally, I will look at the empirical findings of this volume before concluding with some words on the potential research agenda ahead.

\section{The concept of trust}

In the introduction to this volume, the concept of trust is defined as slippery. Trust certainly is not an easy concept since it is not directly observable. It takes many forms and contains a number of functions in the vernacular - partly depending on the language in question. Diverging definitions of trust can be seen as competing constitutive theories. Still, the very basic understanding of trust as a belief that the other does what it should do and at least does not intend to cheat or cause harm in the conditions of uncertainty seems to be shared (Hoffmann 2002; Michel 2013; see also PytlikZillig and Kimbrough 2016).

Indeed, trust is not normally seen as an 'essentially contested concept' (see e.g. Collier, Hidalgo and Maciuceanu 2006), although approaches and perspectives to studying trust vary according to subjects and objects of trust. Trust has normative components - for example, the question of whether trust creates obligations - that can be contested, but discussing and disagreeing over those components has not so far been at the core of trust research. 'Unpacking' the concept of trust is still important since understanding its temporal, cultural, linguistic, political and theoretical layers enables us to think more comprehensively and be conscious about the limits of fixing the meaning of a concept (Berenskoetter 2016).

It seems that the most theory-relevant conceptual discussion is related to the degree to which trust is a rational belief or an emotion - or an emotional belief (Mercer 2010). For many, the concept of trust entails some emotional dimension and therefore conceptualising trust as a cognitive concept distorts its meaning. This debate is related to the distinction between the notions of trust and confidence where confidence is more cognitively constructed and based more on past experiences than trust.

The other salient conceptual issue in analysing trust is to distinguish between distrust and mistrust: mistrust being the absence of trust and distrust its emotionally loaded opposite. Overall, the authors of this volume tend to think that trust is not an absolute either-or concept but one that varies in degrees. But it is not clear if trust and distrust are just opposite ends of the same scale. There are some research findings that support the view that trust and distrust are better to be analysed not as a continuum but as two distinct dimensions: The sources of trust and distrust can be different. For example, Martin Reimann, Oliver Schilke and Karen Cook (2017) have argued that the disposition to trust is explained to some extent by heritability but not by shared socialisation, whereas the disposition to distrust is explained by shared socialisation but not by heritability.

\section{Theoretical approaches to trust}

This volume is based on the idea that there are three key approaches to the study of trust in International Relations: rational, psychological and constructivist. This tripartite typology for 
theorising trust in IR is elegantly put forward by Jan Ruzicka and Vincent Keating (2015). Similar typologies has been presented by other scholars, too. For example, Christer Pursiainen and Angelica Matveeva (2016) employ a parallel theoretical framework to study trust at the end of the Cold War (see also e.g. Weinhardt 2015).

Rational approaches perceive trust as being based on calculation as to whether it is wise to trust the other party in conditions of uncertainty. The key questions deal with the information available concerning the interests and structural constraints of the trustee as well as the degree of control that the trustor can impose. In the rational approach, trust depends on a cost-benefit analysis since it is rational to trust if the expected gains are high. And vice versa, if the potential losses are higher than the gains, distrust prevails. In the framework of principal-agent theory, it can be asked what the optimal amount of trust is compared to control.

Psychological approaches stress that trust is more based on intuition than calculation, and trust formation is dependent on many situational factors that trigger the propensity to trust the other. Positive emotions, such as happiness, are likely to increase trust while negative emotions, such as anger, are a conducive trigger for distrust (Dunn and Schweitzer 2005). Another type of key claim here is that certain personality traits are more conducive to the creation of trusting relations. Some people tend to be more trusting than others, and this distinction often distinguishes political left from right (Rathbun 2012). Individuals whose ancestors were heavily raided during the slave trade are less trusting today (Nunn 2012).

Finally, constructivist approaches to trust in IR tend to emphasise the role of identities in trustbuilding: the more similar and closer in identity terms the parties are, the easier it is for them to trust each other. Constructivist theorising of trust can also specify what kind of norms and rules are likely to invoke trust. Some constructivists pay more attention to the role of language and discourses in the construction of trusting relationships.

These three approaches to study trust are not exhaustive. There are, for example, biological, hormonal, neuropsychological and psychoanalytical approaches to trust that can be applied also in the field of IR (on neuropsychology and trust in IR, see Kugler and Zak 2018). It is partly unclear whether postmodernist theories can offer an alternative account of trust. To the extent that postmodern or poststructuralist approaches can be set apart from constructivism, they can be seen as second-order theories that deal with the linguistic construction and underlying assumptions concerning trust. From the outset, however, postmodernism can be seen as antithetical to the concept of trust because of its critical attitude towards existing representations (Hassan 2003). Indeed, the dichotomy of trust and distrust where trust is always positive and distrust negative can be deconstructed. Such a deconstruction can be supported by psychological studies showing that distrust can free the mind and lead to less stereotypical thinking than trust (Posten and Mussweiler 2013).

Theoretically, trust research can also be divided depending on the level of analysis. This is one of the recurrent themes of this volume and should not be confused with the three approaches above since all the theories can deal with several levels. The paradigmatic case for studying trust is often on the interpersonal level. Yet, both the subject as well as the object of trust can be an institution or a group. The idea of isomorphism between these levels may not hold. Therefore IR scholars can and should 
contribute to the overall theorizing of trust. While trust research in IR often focuses on state leaders, it also aims to theorise trust between states or nations.

It is not always clear how collectives such as 'states' or 'nations' can trust each other, other than as aggregates of individuals. However, individuals often think and act in terms of the extended self of the nation or state, and those who represent the state are also obliged to do so. Moreover, besides the individual and states and nations as collective entities, there are also elites or bureaucratic agencies that can have their own dispositions and develop their own cultures of trust.

The level of analysis problem in trust research has no simple solution when it comes to the question of relative explanatory power. Whereas Brian Rathbun (2012) has put emphasis on individual dispositions, most chapters in this volume tend to pay more attention to collective cultures and representations. As the constructivist literature suggests, there are collective traditions and representations that create and sustain cultures of trust.

As trust is relational and contextual, it is also interesting to theorise contexts such as how trust varies depending on the issue area and other contextual frames (Ruzicka and Keating 2015, 22). The standard view is that in the security policy issues trust is more difficult to build than in other issues areas, but this can be a fallible starting point if generalised too readily. The European members of the NATO alliance may have trusted the US in security policy, for example, but not necessarily when it comes to the environmental policy. This variation of trust across contexts has no single explanation but can also be probed through rational, psychological and constructivist perspectives.

Moreover, trust is an expectation that is relative to the object of trust, but expectations also have a psychological baseline relative to time and past experiences. This is a theme that is discussed in many chapters of this volume. To start with, trust often grows procedurally since beliefs about others' trustworthiness tend to be self-reinforcing. However, there are limits to this growth of trust. The more trust there is, the easier it is to feel betrayed as the expectations of what trust entails also become higher.

From a psychological perspective, even minor experiences of distrust lead to lower levels of trust. Experiences of distrust can have more negative consequences for cooperation than no experiences of distrust on a lower level of trust, since misplaced trust is emotionally more charging than no trust at all. This leads to an idea that there could be a pendulum cycle in the development of trust. Trust develops up to a point where disappointments follow, but it can also degenerate to a point where it is again more likely that surprises are positive.

The three perspectives to trust - rational, psychological and constructivist - do not directly match with the grand theories of IR - realist, liberal and constructivist paradigms. The standard view is that realism is a theory that does not pay much attention to trust, but there is actually a theory of distrust embedded in the realist paradigm drawing - often implicitly - on rational, psychological as well constructivist insights. A rationalist perspective to trust, in turn, can be mainly associated with the liberal theory, while the constructivist theory can subsume both psychological and larger cultural and discursive perspectives. However, these definitions and boundaries of the grand theories are often contested, and therefore alternative conceptualisations can also be justified. 
The point here is that the key in the trichotomy within trust research in IR is not so much the general assumption of the nature of the international system as defined by grand theories but the underlying theory of microfoundations (Rathbun 2009). These microfoundations can be typologised in different ways but a classic way of distinguishing them is Max Weber's (1978 [1922]) taxonomy of instrumental (strategic), value-ethical (normative), affective (emotional) and traditional (habitual) rationality coupled with Jürgen Habermas' communicative rationality.

Yet, this taxonomy does not match directly with the three approaches to trust above. The rational approach corresponds with instrumental rationality, while the psychological perspective can be most easily associated with emotional rationality. Constructivist approaches can cover both value-ethical and affective rationalities as well as communicative rationalities. This suggest that a more explicit theory of microfoundations might lead to even more nuanced frameworks for studying trust than the conventional tripartite scheme. Also, normative and habitual conceptualisations of trust may lead to separate perspectives as the growing popularity of practice theory indicates (Hopf 2010).

The editors and authors of this volume do not propose that one perspective to trust would be superior to others. Such a claim is unnecessary to the extent that they are not mutually exclusive. Many people think that a rational approach to trust could be omitted because trust that is based on calculation is actually not trust at all, which means that calling it trust is superfluous. Yet, the rational approach to trust is valuable at least in setting a baseline to psychological and constructivist approaches to trust.

Moreover, if trust tends to grow procedurally, different sources of trust can play a more significant role on various stages in the course of this development. The key question as to where the rational and psychological perspectives differ is whether control increases or diminishes the likelihood of trust. Apart from that, they rather complement each other than compete directly. The rational, psychological and constructivist approaches to trust are hence not mutually exclusive, but a research strategy based on theoretical pluralism and analytical eclecticism can be adopted. In empirical contexts, the relative interpretative fit, the explanatory power or other gains of these diverse approaches can, however, be put into test.

\section{The methods and empirical knowledge of trust}

There is no simple way to study trust empirically. We can have theoretical circumstantial knowledge of relationships and situations where trust or distrust is likely to prevail. Those propositions can be backed by studies, for example experimental ones, on the basis of which we may conclude via analogical reasoning whether it is plausible that trust or distrust exists. But empirical research in IR must rely on a combination of verbal and behavioral indices (Hoffmann 2002).

Trust researcher often studies texts and statements, but the language itself is fallible. Paradoxically, the language of trust is perhaps most needed in situations where there might be an intention to build trust but where there is also simultaneously plenty of uncertainty concerning whether trust actually exists. If trust exists and is taken for granted, there is no similar need to directly stress it. Behavioral indicators offer no panacea either.

Cooperation is no direct indicator of trust since parties can cooperate without actually trusting each other. This is the case when they are, for example, forced to do so. There are also situations where parties trust each other but do not necessarily cooperate if there is no need for cooperation. To 
overcome this problem, Aaron Hoffmann (2002) regards the absence of oversight mechanisms as a good indicator of trust. Keating and Ruzicka (2014), for their part, point towards the absence of hedging strategies in analysing trusting relations. Arguably, these are better indicators than cooperation as such, but the mere absence of control mechanisms or hedging strategies does not necessarily prove that trust exists any more than their presence automatically distrust.s.

A lot of trust research is based on key examples, both negative and positive, of trust-building between enemies in situations where interpersonal relations between leaders are paramount (Wheeler 2018). Process-tracing and cross-case comparisons help to build knowledge concerning trust. In this volume, there are case studies that represent a variety of cases and examine not only the leaders but also foreign policy elites and societies. Asking the classic question of 'what is this a case of' (see e.g. George and Bennett 2005 and Levy 2008)) can (even though one should not commit to the empiricist research programme often underlying such question) help systematise findings and create interesting research puzzles.

The case studies in this volume address new terrains, illustrate theoretical innovations and address anomalies. So far relatively scant research has been conducted on the role of trust in the European Union foreign policy. The EU is a special case in among international actors because of its hybrid nature. In their chapter, Hiski Haukkala and Sinikukka Saari examine the relations between the EU Russia relations, defining it as a case where personal and emotional trust has not been enough to create a truly trusting relationship between them. Expectations that were set too high led to the erosion of trust, although there could have been rational reasons for enhancing trust.

This is not very different from Johanna Vuorelma's case of trust between Turkey and the European Union - or by extension the West. Vuorelma highlights what role trust plays in an asymmetric relationship describing how opinion makers in the EU are using the language of trust in framing and imposing the right policy choices for Turkey. This again enhances the sense of distrust on Turkey's side. Both EU-Russia and EU-Turkey relations can be seen as cases of how democratic and nondemocratic states, at least in terms of the self-understanding of the other party, have difficulty in building trust.

Carina van de Wetering focuses on United States and India, showing how, despite a shared democratic identity, distrustful relations endured during the Cold War. Since democracy is a discursive construction, it did not in itself result in a trusting relationship between the two, but underlying identity constructions, emotions and practices contributed to insecurity and mistrust. Ville Sinkkonen, in turn, analyses the relationship between the United States and Egypt. Sinkkonen's analysis is an example of how a relative high level of interpersonal or inter-elite trust is not enough for sustaining trusting relationships between states if there is a high level of distrust within the societal level. Scott Edwards discusses how the rational perspective to trust best captures the dynamics in the creation of ASEAN, a group of mostly non-democratic states. The case shows both the significance but also the thinness of rational trust: while it has helped to kick off cooperation and preserve peace in the region, it has not led to a deeper security community shaped by a high level of trust.

Finally, there are cases where we would expect to encounter relatively high levels of trust. Tapio Juntunen and Matti Pesu analyse trust in Finnish-Swedish relations that is an interesting case of two historically close, democratic neighbours with highly trusting societies that still harbor suspicions 
against each other in the field of security cooperation. The mistrust in this case originates from past experiences of misplaced trust combined with the realist worldview that trusting a small state does not pay off since in times of crisis they do not have much freedom of choice despite of benevolent intentions.

On the basis of these empirical chapters, we can draw both pessimist and optimist conclusions. To some degree, the chapters confirm the realist wisdom that building trust among states or societies or even between state leaders in the international arena is not an easy task. Even those societies or leaders that have high levels of trust are not immune to rapid spiraling down when it comes to the level of trust. On the other hand, there are also some positive lessons. Trust building is possible between states, and efforts to cultivate trust in the international system often pay off since even a relatively small amount of trust can make a difference in policy outcomes.

\section{The research agenda ahead}

Trust is an important concept in human and social life that has not yet been studied exhaustively in IR. Although research on trust should form a multidisciplinary endeavor, it must be better embedded in the study of IR. If trust is relational and contextual, IR scholars need to drive their own research agenda while at the same time not losing sight of trust research in other disciplines. In this concluding chapter, various suggestions for future research has already been proposed.

Many trust researchers, such as Keating and Ruzicka (2015), have put forward their own, partly overlapping ideas concerning future research. If more systematic research of the various contexts and relationships was carried out, we could create some more cumulative knowledge on the causes and effects of trust. Moreover, second order research on the concept and representations of trust is also certainly needed. Yet, the gap between first order research and second order research should not be too wide. They could be seen as two distinct research programmes that both suffer from certain thinness of reflection.

Trust research in International Relations is not exactly a research programme, since it has no clearly defined theoretical core from where empirical hypothesis testing expands (see e.g. Elman and Elman 2002). The proliferation of research has therefore not led to much theoretically cumulative knowledge but to a greater awareness of the basic themes and issues at stake and a growing number of empirical applications. Fred Chernoff (2014) has argued that progress depends on the degree of agreement about the criteria for good explanation and the ability to address more clearly defined research puzzles. This does not preclude multiple perspectives and approaches to trust but suggests that we need more rigorously defined questions and a more explicitly pronounced objectives and criteria of assessment.

In sum, research on trust has become more prevalent in International Relations as the political significance of the theme has been increasingly recognised. We already have a much sharper conceptual and theoretical tools and a multifaceted set of empirical knowledge than twenty years ago. Yet, many questions related to trust and distrust are only preliminarily explored in IR. We can trust that research on trust will flourish also in the future.

\section{References}

Berenskoetter, F. (2016) 'Unpacking Concepts', in F. Berendskoetter (ed.) Concepts in World Politics Sage, London 
Chernoff, F. (2014) Explanation and Progress in Security Studies: Bridging Theoretical Divides in International Relations Stanford University Press, Stanford

Collier, D., Hidalgo, F. and Maciuceanu, A. (2006) 'Essentially contested concepts: Debates and applications' Journal of Political Ideologies 11(3) 211-246

Diez T., Bode I., A. Costa, F. (eds) (2011) Key Concepts in International Relations Sage, London

Dunn, J. and Schweitzer, M. (2005) 'Feeling and believing: the influence of emotion on trust' Journal of Personality and Social Psychology 88(5) 736-48

Elman, C. and M. Fendius Elman (2002) 'Introduction: Appraising Progress in International Relations Theory' in Elman C and Elman M F (eds) Progress in International Relations Theory: Metrics and Methods of Scientific Change. MIT Press, Cambridge, Mass

George, A. and Bennett A. (2005) Case Studies and Theory Development in the Social Sciences MIT Press, Cambridge, MA

Hassan, I. (2003) 'Realism, Truth, and Trust in Postmodern Perspective' Third Text 17(1) 1-13 Hoffman, A. (2002) 'A conceptualization of trust in international relations' European Journal of International Relations 8(3) 375-401

Hopf, T. (2010) 'The Logic of Habit in International Relations' European Journal of International Relations 16 (4) 539-561.

Hupcey J, J. Penrod, J. Morse and C. Mitcham (2001) 'An exploration and advancement of the concept of trust' Journal of Advanced Nursing 36(2) 282-93.

Keating, V. and Ruzicka J. (2014) 'Trusting relationships in international politics: No need to hedge' Review of International Studies 40(4) 753-770

Kugler, J. and Zak, P. J. (2018) 'Trust, Cooperation, and Conflict: Neuropolitics and International Relations' in Steve Yetiv and Patrick James (eds) Advancing Interdisciplinary Approaches to International Relations Palgrave, London

Levy, J. (2008) 'Case Studies: Types, Designs and Logics of Inference' Conflict Management and Peace Science 25 (1) 1-18

Li, P. P. (2017) 'Editorial: The time for transition: Future trust research' Journal of Trust Research 7(1) $1-14$

Mercer, J. (2010) 'Emotional Beliefs' International Organization 64(1) 1-31

Michel, T. (2013) 'Time to get emotional: Phronetic reflections on the concept of trust in International Relations' European Journal of International Relations 19(4) 869-890

Neal, T., PytlikZillig, L., Shockley E. and Bornstein B. (2016) 'Inspiring and Advancing the ManyDisciplined Study of Institutional Trust' in Shockley, E., Neal, T.M.S., PytlikZillig, L.M., Bornstein, B.H. (eds) Interdisciplinary Perspectives on Trust: Towards Theoretical and Methodological Integration Springer, New York 
Nunn, N., and Wantchekon L. (2011) 'The Slave Trade and the Origins of Mistrust in Africa' American Economic Review 101(7) 3221-3252

Posten, A.C. and Mussweiler, T. (2013) 'When distrust frees your mind: the stereotype-reducing effects of distrust', Journal of Personality and Social Psychology 105(4) 567-84

Pursiainen, C. and Matveeva A. (2016) 'Initiating Trust in High Politics: The Gorbachev-Reagan Summit in Geneva 1985' International Negotiation 21(1) 104-134

PytlikZillig L. and Kimbrough, C. (2016) 'Consensus on Conceptualizations and Definitions of Trust: Are We There Yet?' in Shockley, E., Neal, T.M.S., PytlikZillig, L.M., Bornstein, B.H. (eds) Interdisciplinary Perspectives on Trust: Towards Theoretical and Methodological Integration Springer, New York

Rathbun, B. (2009) 'It takes all Types: Social Psychology, Trust and the International Relations Paradigms in Our Minds' International Theory 1(3) 345-380

Rathbun, B. (2012) Trust in International Cooperation: International Security Institutions, Domestic Politics and American Multilateralism Cambridge University Press, Cambridge

Reimann, M., Schilke, O. and Cook, K. (2017) 'Trust is heritable, whereas distrust is not' Proceedings of The National Academy of Sciences of The United States of America 114(27) 70077012

Roach, S., Griffiths, M. and O'Callaghan, T. (eds) (2014) International Relations: The Key Concepts $3^{\text {rd }}$ ed. Routledge, Abingdon

Ruzicka, J. and Keating V. C. (2015) 'Going global: Trust research and international relations' Journal of Trust Research 5(1) 8-26

Weber, M. (1978 [1922]) Economy and Society. An Outline of Interpretive Sociology University of California Press, Berkeley

Weinhardt, C. (2015) 'Relational trust in international cooperation: The case of North-South trade negotiations' Journal of Trust Research 5(1) 27-54

Wheeler, N. (2018) Trusting Enemies Oxford University Press, Oxford

Zmerli, S. and Tom W.G. van der Meer (2017) 'The Deeply Rooted Concern with Political Trust' in Zmerli, S Tom W.G. van der Meer (eds) Handbook on Political Trust Edward Elgar, Cheltenham 